\title{
Temporal and spatial expression patterns of Cdc25 phosphatase isoforms during early Xenopus development
}

\author{
NOBUSHIGE NAKAJO*,1,YU-KI DENO ${ }^{1}$, HIROYUKI UENO ${ }^{1}, \mathrm{CHIHIRO} \mathrm{KENMOCHI}^{1}$, \\ KEN SHIMUTA ${ }^{2}$ and NORIYUKI SAGATA ${ }^{1}$ \\ ${ }^{1}$ Department of Biology, Graduate School of Sciences, Kyushu University, Fukuoka, Japan and \\ ${ }^{2}$ Department of Bacteriology I, National Institute of Infectious Diseases, Tokyo, Japan
}

\begin{abstract}
In early animal development, cell proliferation and differentiation are tightly linked and coordinated. It is important, therefore, to know how the cell cycle is controlled during early development. Cdc25 phosphatases activate cyclin-dependent kinases (Cdks) and thereby promote cell-cycle progression. In Xenopus laevis, three isoforms of cdc25 have been identified, viz. cdc25A, cdc25B and $c d c 25 C$. In this study, we isolated a cDNA encoding a novel Xenopus Cdc25 phosphatase (named cdc25D). We investigated the temporal and spatial expression patterns of the four cdc25 isoforms during early Xenopus development, using RT-PCR and whole-mount in situ hybridization. cdc25A and $c d c 25 C$ were expressed both maternally and zygotically, whereas cdc25B and cdc25D were expressed zygotically. Both $c d c 25 A$ and $c d c 25 C$ were expressed mainly in prospective neural regions, whereas $c d c 25 B$ was expressed preferentially in the central nervous system (CNS), such as the spinal cord and the brain. Interestingly, cdc25D was expressed in the epidermal ectoderm of the late-neurula embryo, and in the liver diverticulum endoderm of the mid-tailbud embryo. In agreement with the spatial expression patterns in whole embryos, inhibition of bone morphogenetic protein (BMP), a crucial step for neural induction, induced an upregulation of $c d c 25 B$, but a downregulation of $c d c 25 D$ in animal cap assays. These results indicate that different $c d c 25$ isoforms are differently expressed and play different roles during early Xenopus development.
\end{abstract}

KEY WORDS: cell cycle, Xenopus, cdc25, cdc25D, cell proliferation

In early animal development, cell-cycle progression and exit from the cell cycle must be precisely controlled, since aberrant cell proliferation results in malformation or hyperplasia. It is important, therefore, to know how the cell cycle is controlled during development. Despite the importance of cell-cycle control in embryogenesis, however, relatively less attention has been paid to the expression patterns of cell-cycle regulators than to those of other factors that are involved in patterning and differentiation. Since amphibian Xenopus laevis is one of the most intensely investigated model animals in both developmental biology and cell-cycle control at the molecular level, this animal is highly suitable for studies on the cell-cycle control during embryogenesis.

Over the last three decades, numerous studies have contributed to the understanding of the core mechanisms underlying cell-cycle control. Especially, extensive studies in yeast and mammalian cultured cells have identified many essential regulators that govern cell-cycle progression (Coleman and Dunphy, 1994; Morgan, 1995). Master regulators of cell-cycle progression are the cyclin-dependent kinases (Cdks), which are activated periodically for proper cell-cycle progression (Coleman and Dunphy, 1994; Morgan, 1995). Both Wee1 and Myt1 kinases phosphrorylate and inactivate Cdks to prevent precocious Cdks activation (Coleman and Dunphy, 1994; Morgan, 1995). Cdc25 phosphatases dephospholylate and activate Cdks and thereby promote cell-cycle progression (Coleman and Dunphy, 1994; Morgan, 1995; Boutros et al., 2006). While the spatial expression patterns of cdks, cyclins and wee1/myt 1 during early Xenopus development have been shown in previous studies (Vernon and Philpott, 2003; Leise and Mueller, 2002), those of

Abbreviations used in this paper: BMP, bone morphogenetic protein; Cdk, cyclindependent kinase.

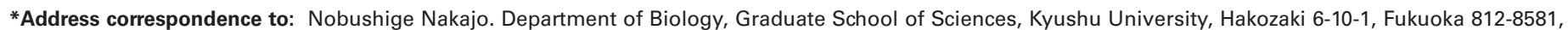
Japan.Tel/Fax: +81-92-642-2617. e-mail: nnakascb@kyushu-u.org - web: http://www.biology.kyushu-u.ac.jp/ hassei/sagata/sagata-top.html
}

Supplementary Material (two figures) for this paper is available at: http://dx.doi.org/10.1387/ijdb.113287nn

Accepted: 24 June 2011. Final, author-corrected PDF published online: 5 August 2011. Edited by: Makoto Asashima 
cdc25 genes have not been described yet.

There are three $c d c 25$ isoforms, cdc25A, cdc25B and cdc25C, in mammalians and Xenopus laevis (Boutros et al., 2006). During early Xenopus development, Cdc25C proteins are constantly expressed in both oocytes and early embryos (Hartley et al., 1996), whereas Cdc25A proteins are abundant in cleavage-stage embryos and degraded rapidly at the midblastula transition (MBT) (Kim et al., 1999; Shimuta et al., 2002). While both cdc25A and $c d c 25 C$ are expressed in early cleavage-stage embryos, cdc25B is not expressed until the MBT (Ueno et al., 2008). After the MBT, however, $c d c 25 B$ is expressed in the neuroectoderm of early neurula embryos, and is essential for primary neurogenesis (Ueno et al., 2008). Although Cdc25 phosphatases are expressed in early Xenopus development, their roles in morphogenesis are poorly understood.

In this study, we have isolated a novel Xenopus cdc25 isoform (termed Xcdc25D; GeneBankAccession No. AB601986), and have examined the expression patterns of $c d c 25$ isoforms (including $X c d c 25 D)$ during early embryogenesis. The spatial expression patterns of $c d c 25 A, c d c 25 B$, and $c d c 25 C$ partially overlapped with each other around the time of neurogenesis, but that of $c d c 25 D$ exhibited a quite distinct pattern from those of the other cdc25 isoforms. Our results provide a framework for future studies on the role of the Cdc25 isoforms in early development.

\section{Results}

\section{cDNA cloning of a novel Xenopus cdc25 isoform}

We performed BLAST search analysis in order to identify a possible novel cdc25 isoform(s) of Xenopus laevis, and found that some EST clones seem to encode a novel isoform. We then obtained a corresponding plasmid from NIBB (GeneBankAccession No. BJ037611), resequenced it, and found that this plasmid indeed contains a cDNAencoding a novel cdc25 isoform. Sequence analysis revealed that the predicted translation product of this cDNA has 413 amino acid residues and, like other cdc25 isoforms, consists of an N-terminal regulatory domain (NRD), a C-terminal phosphatase domain (PD), and a short C-terminal regulatory domain (CRD) (Fig. 1A). Neither the NRD nor the CRD of this Cdc25 isoform shares sequence homology with those of conventional Xenopus Cdc25 isoforms. However, the PD of this Cdc25 isoform shares $52 \%, 53 \%$, and $56 \%$ identities with the PDs of Cdc25A, Cdc25B, and Cdc25C, respectively (Fig. 1B). Apparently, the PD of this isoform, excluding its inserted sequence, is more similar to that of Zebrafish Cdc25d (Nogare et al., 2007) (Fig. 1B), and indeed, phylogenetic analysis showed that this isoform is most closely related to Zebrafish Cdc25d (Fig. 1C). Thus, hereafter, we call this Xenopus cdc25isoform (X)cdc25D. A clear orthologue of $c d c 25 D$ was found easily by BLAST in Xenopus tropicalis (GenBankAccession No. CR575588), but, interestingly, not in mammalians or chickens.

\section{Temporal expression patterns of cdc25 isoforms during early Xeno- pus development}

By RT-PCR, we first investigated the temporal expression patterns of $c d c 25$ isoforms during early $\mathrm{Xe}$ nopus development. In agreement

Fig. 1. Sequence analysis of the $X c d c 25 D$ product. (A) A schematic representation of Xenopus Cdc25 isoforms. Three structural domains, i.e. the $N R D$, the $P D$, and the $C R D$, were defined according to Fauman et al., (1998). (B) Alignment of the PD of Cdc25 proteins. Accession numbers are as in (C). D, Drosophila Melanogaster; $X$, Xenopus laevis; $H$, Homo sapiens; Z, Zebra rerio. (C) Phylogenetic tree ofcdc25 genes from various species, constructed by using the neighbor-joining method. Accession numbers used are shown. 


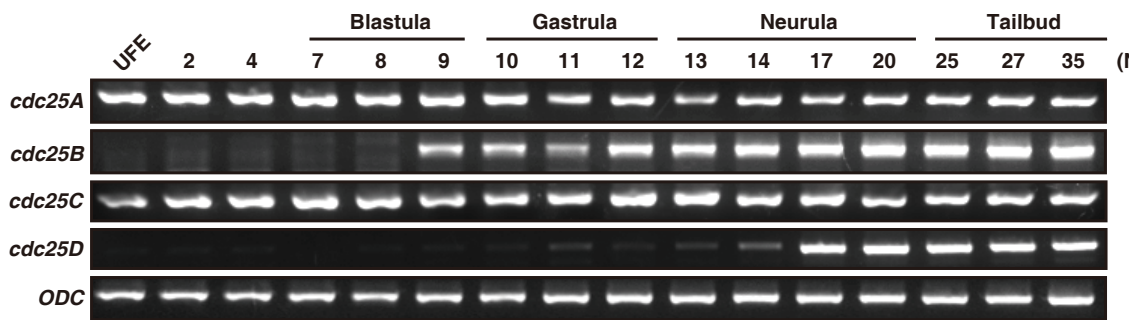

Fig. 2. Temporal expression patterns of $c d c 25$ isoforms during early Xenopus development. The transcripts of Xenopus cdc25 isoforms were analyzed by RT-PCR. ODC (ornithine decarboxylase) is a loading control. Nieuwkoop-Faber (N/F) stages are shown at the top.

with previous reports (Kim et al., 1999; Ueno et al., 2008; Hartley et al., 1996), cdc25A transcripts were constantly present at the cleavage stages with a slight decrease in its levels at later stages, cdc25Btranscripts were expressed after the midblastula stage, and cdc25C transcripts were constantly present throughout the stages of early embryogenesis (Fig. 2). In contrast, cdc25D transcripts were scarcely detected at the preneurula stages, but became detectable during neurulation and persisted at least up to the late tailbud stage (Fig. 2). Thus, cdc25A and $c d c 25 C$ are expressed both maternally and zygotically, whereas cdc25B and cdc25D are expressed zygotically in early Xenopus development.

\section{Spatial expression patterns of cdc25 isoforms during early Xenopus development}

Although the spatial expression patterns of several cell-cycle regulators, such as cdks, cyclins, wee1 and myt1 isoforms, during early Xenopus development have been shown in previous studies (Vernon and Philpott, 2003; Leise and Muller, 2002), those of cdc25 isoforms have not been reported. We therefore examined the spatial expression patterns of Xenopus cdc25 isoforms using whole-mount in situ hybridization. In these experiments, no specific signals were detected with any of the sense probes (Fig. 3 M,N,O,P). Using an antisense probe, however, cdc25A transcripts were detected principally in the animal hemisphere from the blastula to initial gastrula stages (Fig. $3 \mathrm{~A}, \mathrm{E}$ ), and in the anterior neural plate at the early neurula stage (Fig. 3I). At the late neurula stage, cdc25A was expressed in the neural fold and the neural crest (Fig. 3Q), and, at the tailbud stage, it was weakly expressed in prospective retinal layers in eye vesicles (Fig 4 A,E, I). cripts were not detectable in blastula embryos (Fig. 3B). During gastrulation, $c d c 25 B$ transcripts were expressed in both the ectodermal and mesodermal regions (Fig. 3F). As previously reported (Ueno et al., 2008), at the early neurula stage, cdc25B transcripts exhibited bilateral expressions in the neural plate and trigeminal ganglions (Fig. $3 \mathrm{~J}, U$ ), and, at the late neurula stage, they were expressed in the regions undergoing neurogenesis, such as the neural fold and eye anlagen (Fig. 3R). Furthermore, at the tailbud stage, $c d c 25 B$ transcripts were expressed in the central nervous system, such as the spinal cord and the brain, including prosen-
Consistent with the results of RT-PCR (Fig. 2), cdc25B trans-

cephalon, mesencephalon and rombencephalon (Fig. 4 B,F); they were also strongly expressed in the prospective retinal layers of eye vesicles (Fig. $4 \mathrm{~B}, \mathrm{~F}, \mathrm{~J}$ ).

$c d c 25 C$, like $c d c 25 A$, was expressed exclusively in the animal hemisphere from the blastula to gastrula stages (Fig. $3 \mathrm{C}, \mathrm{G}$ ). At the early neurula stage, $c d c 25 C$ transcripts were expressed in the
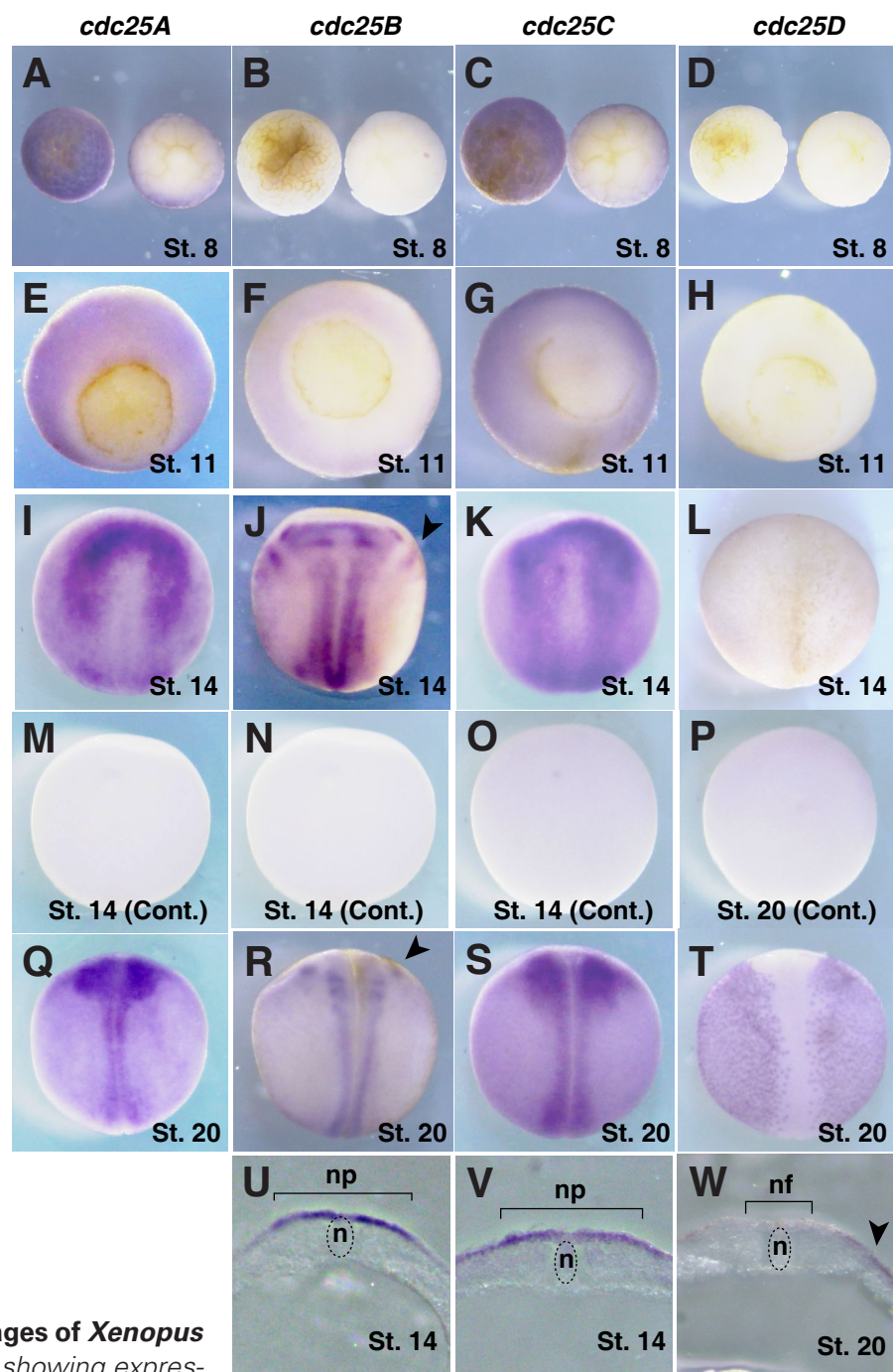

embryos. Whole-mount in situ hybridization (WISH) with antisense probes showing expres-

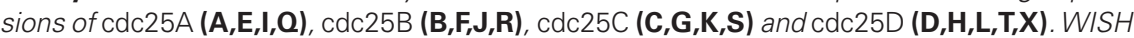
with control sense cdc25A, cdc25B, cdc25C and cdc25D probes (M,N,O,P). (A, B, C, and D) The right and left embryos from vegetal and animal views, respectively. ( $E, F, G$ and $H$ ) Vegetal views. (I, J, K, L, Q, R, S and T) Dorsal views with anterior up. (J) The arrowhead indicates trigeminal ganglion. (R) The arrowhead indicates prospective eye regions. (U) Central transversal section of (J). (V) Central transversal section of (K). (W) Central transversal section of (T); the arrowhead indicates epidermal ectoderm. (X) Magnified view of the epidermal ectoderm of (T). Abbreviations: $n$, notochord; np, neural plate; nf, neural fold. 
neural plate (Fig. $3 \mathrm{~K}, \mathrm{~V}$ ), and, at the late neurula stage, they were detected in the neural fold and neural crest regions (Fig. 3S). At the tailbud stage, cdc25C transcripts were broadly expressed in the head region (Fig. $4 \mathrm{C}, \mathrm{G}$ ), particularly in the prospective retinal layers of eye vesicles (Fig. 4K).

Unlike $c d c 25 A, B$ and $C$ transcripts, $c d c 25 D$ transcripts were undetectable up to the early neurula stage (Fig. $3 \mathrm{D}, \mathrm{H}, \mathrm{L}$ ), consistent with the results of RT-PCR (Fig. 2). Interestingly, at the late neurula stage, however, cdc25D transcripts were expressed in the epidermal ectoderm with a punctuate pattern, but not in the neural region (Fig. $3 \mathrm{~T}, \mathrm{~W}, \mathrm{X}$ ). At the tailbud stage, cdc25D transcripts were barely detected in the epidermal ectoderm, but, interestingly, their expression became apparent in the liver diverticulum endoderm (Fig. 4 D,H,L,M).

\section{The effect of BMP inhibition on transcription of cdc25 isoforms}

Given their spatially (as well as temporally) restricted expression patterns, expressions of different $c d c 25$ isoforms would be regulated in different ways during development. In Xenopus, the ectodermal cell mass of the mid-blastula embryo (animal cap) is pluripotent, and is useful for addressing the developmental signal(s) (Lamb et al., 1993; Henry et al., 1996). Indeed, cdc25B expression in animal caps has been shown to be upregulated by inhibition of bone morphogenetic protein (BMP) (Ueno et al., 2008), a crucial event required for neural induction (Stern, 2005). We therefore investigated whether expression (or transcription) of other cdc25 isoforms would be affected by BMP inhibition, using animal cap assays and RT-PCR. Consistent with our previous report (Ueno et al., 2008), cdc25B transcription in animal caps was readily up-regulated by ectopic expression of noggin, a BMP antagonist (Munoz-Sanjuan and Brivanlou, 2002) (Fig. 5). Transcriptions of $c d c 25 A$ and $C$ were also up-regulated by noggin expression, albeit

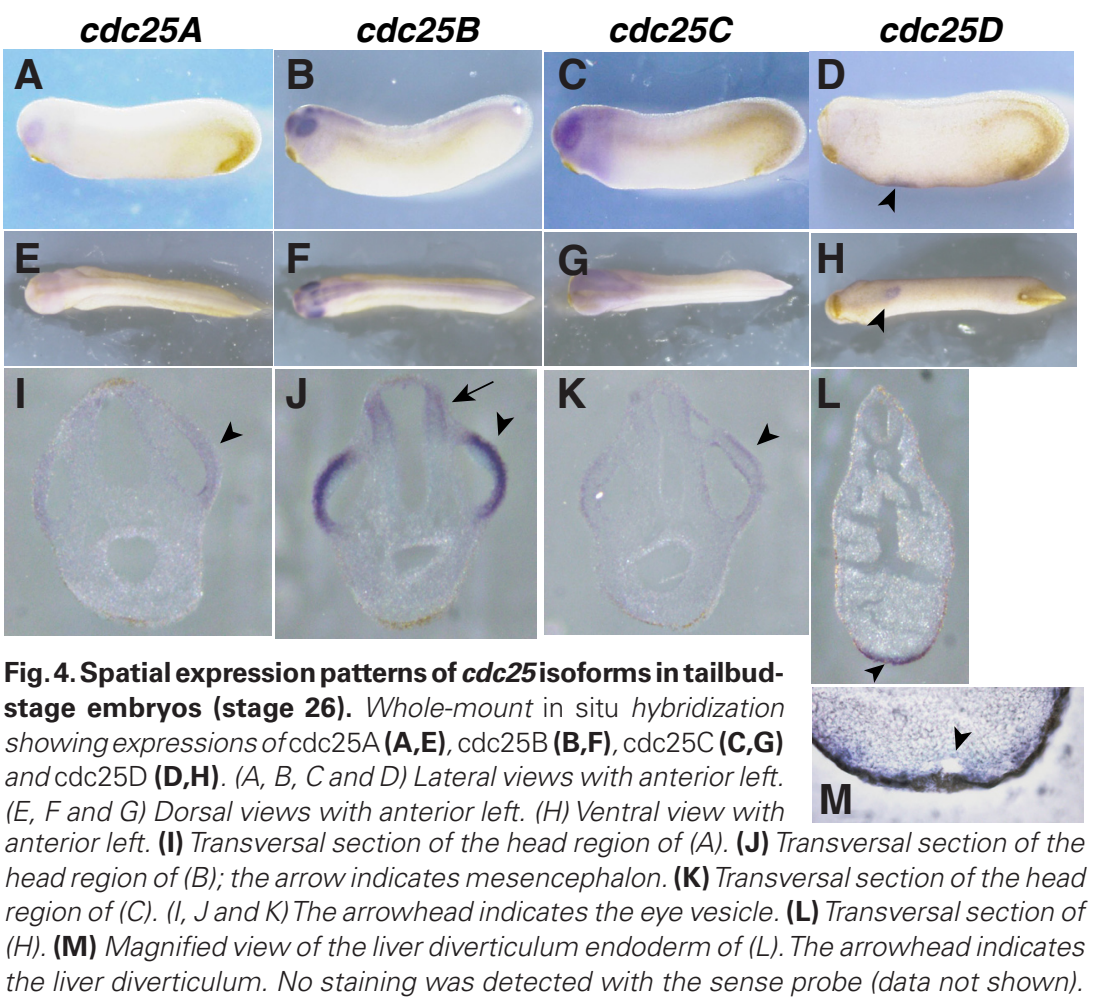

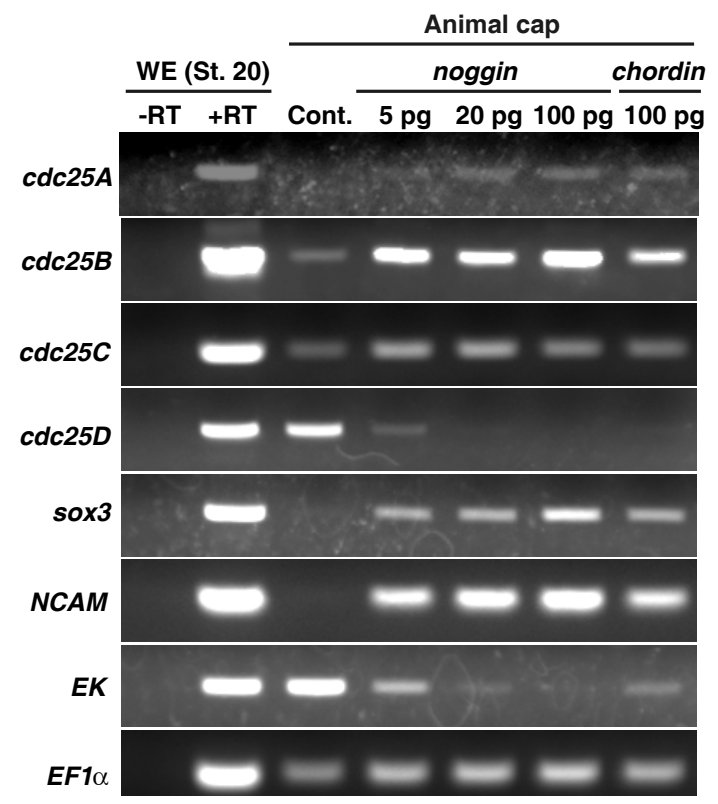

Fig. 5. The effects of BMP inhibition on the expression of $c d c 25$ isoforms in animal caps. Animal caps were isolated from late blastula Xenopus embryos (st. 9) pre-injected with the indicated amounts of noggin orchordin mRNA at the one-cell stage. The animal caps were cultured until sibling control embryos reached st. 20 and then analyzed by RT-PCR. sox 3 and NCAM are downstream markers of noggin and chordin. Epidermal keratin (EK) is a marker for epidermis. EF1 $\alpha$ is a loading control.

to slightly lesser extents than cdc25B transcription; notably, however, $c d c 25 D$ transcription was down-regulated dose-dependently by noggin expression (Fig. 5). Moreover, ectopic expression of chordin, another BMP antagonist (Munoz-Sanjuan and Brivanlou, 2002), similarly affected the expression of cdc25 isoforms (Fig. 5). These results were consistent with the spatial expression patterns of the cdc25 isoforms (Fig. 4). Thus, transcriptions of different cdc25 isoforms are likely to be differently regulated during the process of neural induction.

\section{Discussion}

In this study, we identified a novel isoform of Xenopuscdc25, termed cdc25D. In addition, we investigated the temporal and spatial expression patterns of all isoforms of $c d c 25$ phosphatase during early Xenopus development, and found that they are different from each other during early development.

In agreement with previous studies (Kim etal., 1999; Hartley et al., 1996), cdc25A and $C$ transcripts were expressed at the cleavage and early blastula stages, or maternally. In contrast to these, cdc25B and $D$ transcripts were not expressed maternally. Therefore, Cdc25A and Cdc25C isoforms could contribute to the rapid cell cycles during cleavage stages. Indeed, it has been shown that dominant-negative inhibition of Cdc25Acan delay cell cycles in cleaving embryos (Kim et al., 1999). Previous studies showed that Cdc25C protein exists in oocytes (Izumi et al., 1992; Kumagai 
and Dunphy,W.G., 1992., Nakajo et al., 2000), whereas Cdc25A protein does not (Kim et al., 1999; Shimuta et al., 2002). Thus, Cdc25C protein seems to be the sole cdc25 isoform expressed in Xenopus oocytes, consistent with it being essential for Cdk1 activation during oocyte maturation in Xenopus (Izumi et al., 1992; Kumagai and Dunphy,W.G., 1992).

It has been shown that cells in the neural region actively proliferate during the neurula stage (Saka and Smith, 2001). Around the neurula stage, $c d c 25 A, B$, and $C$ were expressed in the neural region, including the neural plate and the neural fold, and, in animal caps, their expressions were up-regulated by BMP inhibition, which is central to neural induction. Thus, $c d c 25 A-C$ isoforms could promote cell-cycle progression in the neural region. Notably, however, expression of $c d c 25 B$ was more prominent in the neural region, and more readily induced by BMP inhibition in animal caps, than those of $c d c 25 A$ and $C$. These results are consistent with our previous results that $\mathrm{Cdc} 25 \mathrm{~B}$ contributes significantly to cell proliferation in the neural region (Ueno et al., 2008). Previous studies showed that $c d k 1$ and cyclin Btranscripts are also preferentially expressed in the neural region (Vernon and Philpott, 2003), whereas wee1 and myt 1 transcripts, encoding cdk1-inhibitory kinases, are barely expressed in the same region (Leise and Mueller, 2002). Thus, transcriptional regulations of these cell-cycle regulators would also contribute to cell-cycle progression in the neural region.

In contrast to other cdc25 isoforms, cdc25D transcripts were not expressed in the neural region, but were expressed in the epidermal ectoderm of the late-neurula embryos. Moreover, its transcription was suppressed by BMP inhibitors in animal caps. These results suggest that $\mathrm{Cdc} 25 \mathrm{D}$ contributes to cell proliferation in non-neural ectoderms. Particularly, the punctuate expression pattern of $c d c 25 D$ in the epidermal ectoderm of late-neurula embryos resembles that of $\alpha$-tubulin, which is a marker of ciliated cells (Deblandre et al., 1999). Thus, Cdc25D may have some role(s) in the formation of ciliated cell. Furthermore, and interestingly, at the tailbud stage, $c d c 25 D$ transcripts were expressed in the liver diverticulum endoderm, which is the origin of embryonic liver in Xenopus (Nieuwkoop and Faber, 1994). Thus, Cdc25D might also be involved in the formation of embryonic liver.

Xenopus cdc25D has significantly closer homology with zebrafish $c d c 25 d$ than with other conventional $c d c 25$ isoforms. In zebrafish, however, cdc25d is expressed throughout early development and in the restricted ventral mesoderm and nasal placodes of the 24 hpf and 32 hpf embryos (Nogare et al., 2007). Therefore, despite their sequence homology, zebrafish cdc25d and Xenopus cdc25D seem to have different roles in early development. Furthermore, and surprisingly, neither mammalians nor chickens seem to possess the cdc25D gene, suggesting that amniotes might have lost it during evolutionary processes. This might be related, however, to the potentially divergent roles of $c d c 25 D$ even between zebrafish and Xenopus development.

The existence of distinct cdc25 isoforms in vertebrates may represent their different roles during developmental processes. This seems to be true for Xenopus development but not necessarily for mouse development. Recent studies in mice revealed the functional redundancy of $\mathrm{Cdc} 25$ isoforms during development; mice lacking both $c d c 25 B$ and $c d c 25 C$ developed normally, suggesting that $c d$ $c 25 A$ compensates for the loss of $c d c 25 B$ and $c d c 25 C$ (Ferguson et al., 2005). In Xenopus, however, Cdc25A protein, unlike Cdc25B or $\mathrm{C}$ proteins, is largely degraded by Chk1 kinase just after the MBT
(Kim et al., 1999; Shimuta et al., 2002), and thereafter, cdc25A is expressed to very limited regions of the late-neurula and tailbud stage embryos. Thus, it appears that, in Xenopus, Cdc25A cannot compensate for the function of Cdc25B and Cdc25C.

To summarize, the temporal and spatial expression patterns of different $c d c 25$ isoforms are different from each other during early Xenopus development. In addition, each orthologue of Cdc25 isoforms seems to have at least partially different roles in early development of different species.

\section{Materials and Methods}

\section{Cloning of a novel isoform of Xenopus cdc25}

The Xcdc25D EST was obtained from National Institute for Basic Biology (NIBB) with an identifier XL041a15 (GenBank accession number AB601986). The plasmid was resequenced with ABI PRISM 3100 Genetic Analyzer (applied biosystems, USA). Phylogenetic analysis was performed using the ClustalW program.

\section{Xenopus embryos, in vitro transcription and animal cap assays}

Xenopus eggs were artificially fertilized using Xenopus testis homogenates and dejellied with $0.1 \times$ Modified Barth's saline (MBS) containing $2 \%$ cysteine for 20 minutes. Staging of embryos was done according to Nieuwkoop and Faber (1994). Capped RNAs were synthesized in vitro using a MEGAscript SP6 kit (Ambion) and injected into one-cell stage embryos. Injected embryos were cultured in $0.1 \times$ MBS containing $3 \%$ Ficoll at $20^{\circ} \mathrm{C}$. Animal cap cells were obtained from stage $8.5-9$ embryos, and then cultured in 1 x MBS containing $50 \mu \mathrm{g} / \mathrm{ml}$ gentamicin.

\section{RNA extraction and RT-PCR}

Total RNAs were extracted from five whole embryos at various stages and from twenty animal cap explants, using TRIzol reagent (invitrogen). The extracted total RNAs corresponding to one embryo or four animal cap explants were used to synthesize cDNAs using oligo- $\mathrm{dT}_{20}$ primers and SuperScript III reverse transcriptase (invitrogen). One-fortieth of the reaction products were subjected to $\mathrm{PCR}\left(94^{\circ} \mathrm{C}\right.$ for $30 \mathrm{sec}, 52^{\circ} \mathrm{C}$ for $30 \mathrm{sec}$, $72^{\circ} \mathrm{C}$ for $1 \mathrm{~min}$ ) with TAKARA Ex Taq (TAKARA). The PCR products were confirmed for their identities by sequencing and southern blotting (data not shown). The primer sets ( $5^{\prime}$ to $3^{\prime} ; \mathrm{U}$, upstream and D, downstream) and cycles used for PCR were:

cdc25A (27 cycles)

U: GGCCACATACAGGGAGCCATTAACC

D: TAGTTTCTTCAGCCGGCTGTACAGTTC cdc25B (30 cycles)

U: ACGTGGAAGACTTTCTGCTGAAGGAGC

D: TCTCGCTTGCTCTTGTCTCCGGCCC

cdc25C (27 cycles)

U: GGACACATAAAGGGTGCATTAAACC

D: GCTTCATTATGCGGGCAATCTGTTC cdc25D (27 cycles)

U: GACGGAGGGCACATTAAGGGAGCCTAC

D: GCTGGATGTTTTTTCAAGACAGTGC

sox3 (27 cycles)

U: GCGCACATGAACGGCTGGACTA

D: GTGTGGGAGGTGATGGCTGGAG

Primer sets for $N C A M$ (30 cycles), epidermal keratin (20 cycles), and EF1- $\alpha$ (20 cycles) are described in Xenbase (http://www.xenbase.org/common). Under the present RT-PCR conditions, the amounts of the amplified target products were reflecting the amounts of template RNAs (Fig. S1), and the targets were amplified within a linear range of conditions (Fig. S2).

\section{Whole-mount in situ hybridization}

Whole-mount in situ hybridization was performed according to the previously described methods (Harland, 1991), with slight modifications 


\section{N. Nakajo et al.}

described by Takahashi et al., (2006). Open reading frame sequences of Xenopus cdc25A (Okazaki et al., 1996), cdc25B (Ueno et al., 2008), $c d c 25 C$ (Kumagai and Dunphy, 1992) and $c d c 25 D$ were subcloned into the pBlueScript KS+ plasmid (Agilent technologies). These plasmids were linealized, and digoxigenin-labeled RNA probes in sense and antisense orientations were transcribed using MEGAscript T7 and T3 kits (Ambion), respectively. For sectioning, stained embryos were embedded in gelatin/ sucrose (15\% cold fish gelatin and 30\% sucrose in PBS) and mounted with OCT compound (Tissue-Tek OCT compound, Sakura Finetek, USA), and $40 \mu \mathrm{m}$ sections were prepared with a cryostat (Jung FrigoCut, Leica, Germany).

\section{Acknowledgment}

We thank M. Watanabe and S. Takahashi for helpful technical informations, I. Ito and $\mathrm{H}$. Udo for advice of preparing the cryosections, K. Ota for preparing the manuscript, and $M$. Ye for technical supports. This work was supported by a scientific grant from the Ministry of Education, Culture, Sports, Science, and Technology of Japan to N.S.

\section{References}

BOUTROS, R., DOZIER, C., DUCOMMUN, B (2006). The when and wheres of CDC25 phosphatases. Curr. Opin. Cell Biol. 18: 185-191.

BRIVANLOU, A.H., DARNELL, J.E., JR. (2002). Signal transduction and the control of gene expression. Science 295: 813-818.

CHEN, M.S., HUROV, J., WHITE, L.S., WOODFORD-THOMAS, T., PIWNICAWORMS, $\mathrm{H}$ (2001). Absence of apparent phenotype in mice lacking Cdc25C protein phosphatase. Mol. Cell Biol. 21: 3853-3861.

COLEMAN, T. R., DUNPHY, W. G. (1994). Cdc2 regulatory factors. Curr. Opin. Cell. Biol. 6: 877-882.

DEBLANDRE, G.A., WETTSTEIN, D.A., KOYANO-NAKAGAWA, N., KINTNER, C. (1999). A two-step mechanism generates the spacing pattern of the ciliated cells in the skin of Xenopus embryos. Development 126: 4715-4728.

FERGUSON, A.M., WHITE, L.S., DONOVAN, P.J., PIWNICA-WORMS, H. (2005). Normal cell cycle and checkpoint responses in mice and cells lacking Cdc25B and Cdc25C protein phosphatases. Mol. Cell Biol. 25: 2853-2860.

HARTLEY, R.S., REMPEL, R.E., MALLER, J.L. (1996). In vivo regulation of the early embryonic cell cycle in Xenopus. Dev. Biol. 173: 408-419.

HENRY, G.L., BRIVANLOU, I.H., KESSLER, D.S., HEMMATI-BRIVANLOU, A., MEL-
TON, D.A. (1996). TGF- $\beta$ signals and a pattern in Xenopus laevis endoderma development. Development. 122: 1007-1015

IZUMI, T, WALKER, D.H., MALLER, J.L. (1992). Periodic changes in phosphorylation of the Xenopus cdc25 phosphatase regulate its activity. Mol. Biol. Cell. 3: 927-939.

KIM, S.H., LI, C., MALLER, J.L., (1999). A maternal form of the phosphatase Cdc25A regulates early embryonic cell cycles in Xenopus laevis. Dev. Biol. 212: 381-391.

KUMAGAI, A. DUNPHY, W.G. (1992). Regulation of the cdc25 protein during the cell cycle in Xenopus extracts. Cell 70: 139-151.

LAMB, T.M., KNECHT, A.K., SMITH, W.C., STACHEL, S.E., ECONOMIDES, A.N., STAHL, N., YANCOPOLOUS, G.D., HARLAND, R.M. (1993). Neural induction by the secreted polypeptide noggin. Science 262: 713-718.

LEISE, W.L., MUELLER, P.R. (2002). Multiple Cdk1 inhibitory kinases regulate the cell cycle during development. Dev. Biol. 249: 156-173.

MORGAN, D. O. (1995). Principles of CDK regulation. Nature 374: 131-134.

MUNOZ-SANJUAN, I., BRIVANLOU, A.H. (2002). Neural induction, the default model and embryonic stem cells. Nat. Rev. Neurosci. 3: 271-280.

NAKAJO, N., YOSHITOME, S., IWASHITA, J., IIDA, M., UTO, K., UENO, S., OKAMOTO, K. AND SAGATA, N. (2000). Absence of Wee1 ensures the meiotic cell cycle in Xenopus oocytes. Genes Dev. 14: 328-338.

NIEUWKOOP, P.D., FABER, J. (1994). Normal Table of Xenopus laevis (Daudin) Garland Publishing Inc., New York.

NOGARE, D.E., ARGUELLO, A., SAZER, S., LANE, M.E. (2007). Zebrafish cdc25a is expressed during early development and limiting for post-blastoderm cell cycle progression. Dev. Dyn. 236: 3427-3435.

SAKA, Y, SMITH, J.C. (2001). Spatial and temporal patterns of cell division during early Xenopus embryogenesis. Dev. Biol. 229: 307-318.

SHIMUTA, K., NAKAJO, N., UTO, K., HAYANO, Y., OKAZAKI, K., SAGATA, N. (2002) Chk1 is activated transiently and targets Cdc25A for degradation at the Xenopus midblastula transition. EMBO J. 21: 3694-3703.

STERN, C.D. (2005). Neural induction: old problem, new findings, yet more questions Development 132: 2007-2021.

TAKAHASHI, S., ONUMA, Y., YOKOTA, C., WESTMORELAND, J.J., ASASHIMA, M., WRIGHT, C.V. (2006). Nodal-related gene Xnr5 is amplified in the Xenopus genome. Genesis 44: 309-321.

UENO, H., NAKAJO, N., WATANABE, M., ISODA, M., SAGATA, N. (2008). FoxM1driven cell division is required for neuronal differentiation in early Xenopus embryos. Development 135: 2023-2030.

VERNON, A.E., PHILPOTT, A. (2003). The developmental expression of cell cycle regulators in Xenopus laevis. Gene Expr. Patterns 3: 179-192. 


\section{Further Related Reading, published previously in the Int. J. Dev. Biol.}

Cyclin B2/cyclin-dependent kinase1 dissociation precedes CDK1 Thr-161 dephosphorylation upon M-phase promoting factor inactivation in Xenopus laevis cell-free extract Franck Chesnel, Franck Bazile, Aude Pascal and Jacek Z. Kubiak Int. J. Dev. Biol. (2007) 51: 297-305

Expression of the E2F family of transcription factors during murine development Judith C Kusek, Robert M. Greene, Paul Nugent and M. Micheke Pisano Int. J. Dev. Biol. (2000) 44: 267-277 (2000)

p34(cdc2) and mitotic cyclin expression in the developing quail neuroretina. Xavier Espanel, Anne Kastener, Oliver Stettler, Bertrand Tavitian, Gilbert Brun and German Gillet

Int. J. Dev. Biol. (1997) 41: 469-476

Cell reproduction: induction of M-phase events by cyclin-dependent cdc2 Takeo Kishimoto

Int. J. Dev. Biol. (1994) 38: 185-191

Meiosis reinitiation as a model system for the study of cell division and cell differentiation

Pierre Guerrier, Pierre Colas and Isabella Neant Int. J. Dev. Biol. (1990) 34: 93-109

$$
\text { ISI Impact Factor }(2010)=2.86
$$

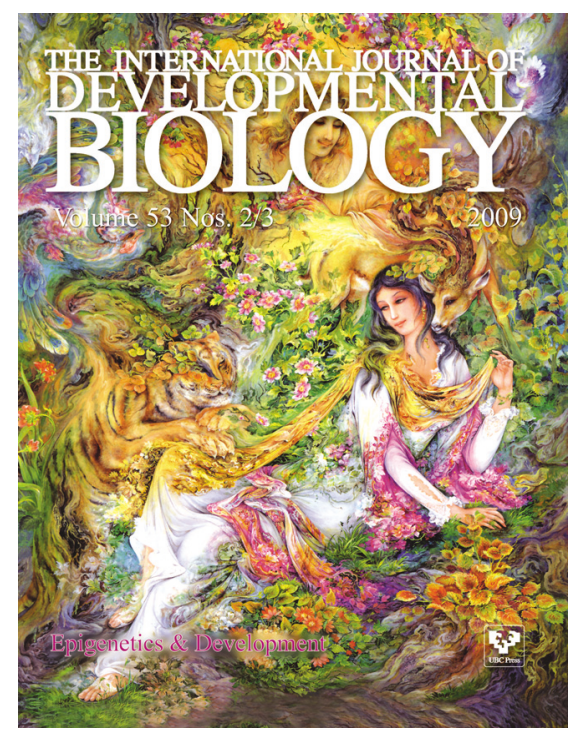

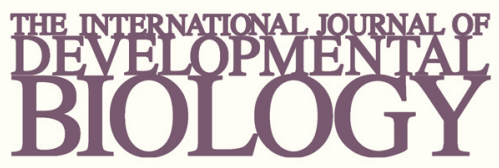

Volume 54 Nos. 6/7
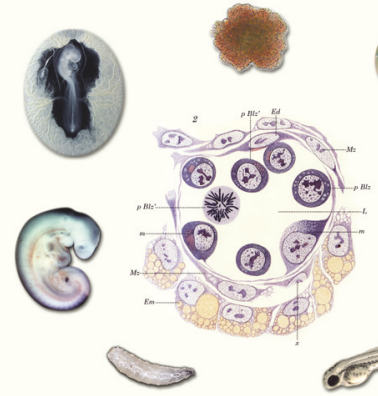

Developmental Hematopoiesis
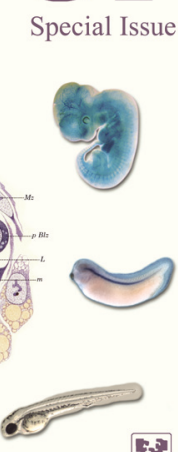

\$
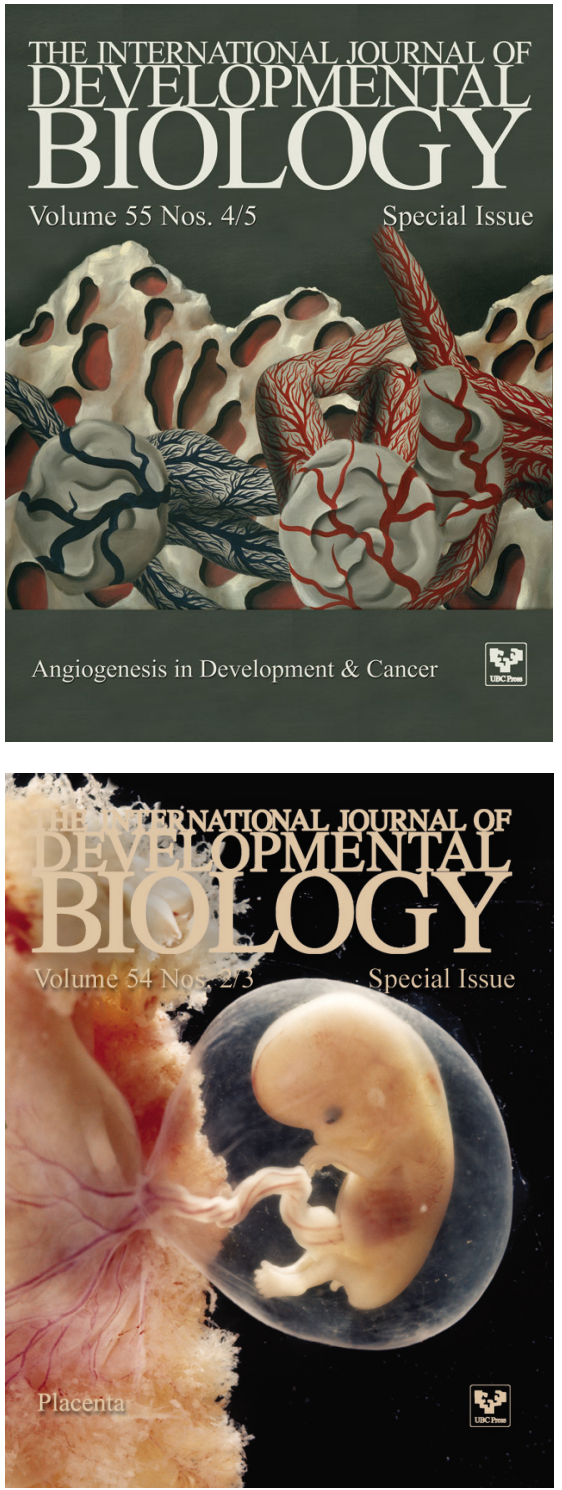